\title{
Cloning of a protopectinase gene of Trichosporon penicillatum and its expression in Saccharomyces cerevisiae
}

\author{
Ken-ichi Iguchi, ${ }^{1}+$ Haruka Hirano, ${ }^{1}$ Masao Kishida, ${ }^{1}$ Haruhiko Kawasaki ${ }^{1}$ \\ and Takuo Sakai ${ }^{1,2}$
}

\author{
Author for correspondence: Takuo Sakai. Tel: +81722521161 ext. 2470. Fax: +81722520341. \\ e-mail: masyksd@biochem.osakafu-u.ac.jp
}

\footnotetext{
1 Department of Applied Biochemistry, College of Agriculture, Osaka Prefecture University, Gakuen-cho 1-1, Sakai, Osaka 593, Japan

2 Department of Food Science, Faculty of Agriculture, Kinki University, 3327-204, Nakamachi, Nara 631 , Japan
}

\begin{abstract}
A protopectinase (PPase)-encoding gene, PSE3, from Trichosporon penicillatum was cloned by colony hybridization using two oligonucleotide probes synthesized from the $\mathbf{N}$-terminal amino acid sequences of native PPase SE1 and one peptide from a lysyl endopeptidase digest. Nucleotide sequencing revealed that PSE3 contains an ORF encoding a 367 amino acid protein. Mature PPase SE3 is composed of $\mathbf{3 4 0}$ amino acids and the $\mathbf{N}$-terminus of the ORF appeared to correspond to a signal peptide and a propeptide processed by a KEX2-like proteinase. The deduced amino acid sequence of PSE3 was 65.4, 56.7, 58.1, 61.8 and $48.9 \%$ homologous to the polygalacturonases of Aspergillus oryzae, Aspergillus niger, Aspergillus tubigensis, Cochliobolus carbonum and Fusarium moniliforme, respectively. One domain, which might interact with polygalacturonic acid, is highly conserved not only in fungal polygalacturonases but also in bacterial and plant polygalacturonases. PSE3 was expressed in Saccharomyces cerevisiae, but three forms (the mature form, a glycosylated form and an uncharacterized processed form) of PPase SE3 were present among the PSE3 products.
\end{abstract}

Keywords: Trichosporon penicillatum, protopectinase, gene cloning, yeast polygalacturonase, Saccharomyces cerevisiae

\section{INTRODUCTION}

Many micro-organisms produce the pectin-solubilizing enzyme protopectinase (PPase), which releases soluble pectin from the protopectin in plant tissues. Two types of PPases have been reported: type A PPases, which are polygalacturonases (PGases), degrade the polygalacturonic acid chains that compose the unsubstituted region (smooth region) of the protopectin structure, and type B PPases degrade the neutral sugar chain which connects the smooth region to the other cell-wall constituents (Sakai et al., 1993). Type A PPases have been purified from yeast strains belonging to Kluyveromyces and Trichosporon species (Sakai \& Okushima, 1978; Sakai et al., 1984). In another study by our group (Iguchi et al., 1996), three PPases (SE1, SE2

†Present address: Plant Biotechnology Division, Corunum Corporation, 1, Takasago 2-chome, Takaishi, Osaka 592, Japan.

Abbreviations: PGase, polygalacturonase; PPase, protopectinase.

The GenBank accession number for the nucleotide sequence reported in this paper is D89650. and SE3) were purified from Trichosporon penicillatum B2 strain, and the ratios of their activity to PGase activity ( $q_{\text {PPase/PGase }}$ ) were shown to be different. We are interested in the activities of these three PPases and their similarities to PGases produced by bacteria, fungi and plants. However, analysis of the two minor PPases (SE2 and SE3) is difficult, since they are produced only in small amounts $(0.15$ and $0.007 \%$ of total PPase, respectively). Isolation of the PPase-encoding genes from a genomic library of $T$. penicillatum B2 is important in order to determine the complete primary structure of the PPases and to prepare large amounts of the minor PPases from transformants of Saccharomyces cerevisiae. The finding that the $\mathrm{N}$-terminal amino acid sequences of PPases SE1, SE2 and SE3 have high homology (Iguchi et al., 1996) suggests that the genes encoding these PPases are highly conserved. Using DNA probes based on sequences common to all three PPase genes but derived from the amino acid sequences of segments of the PPase SE1, which is easily purified from $T$. penicillatum B2 (Iguchi et al., 1996), we succeeded in cloning the gene encoding PPase SE3. 
Here, we describe this cloning, the analysis of the PPase SE3 gene (PSE3), the homology between PPase SE3 and the other proteins, and the production of PPase SE3 by S. cerevisiae.

\section{METHODS}

Strains, culture conditions and chemicals. The T. penicillatum and S. cerevisiae strains used were B2 (Iguchi et al., 1996) and DKD-5DH (MATa trp1 leu2 his3), respectively. Escherichia coli strains used were DH5 $\alpha$ and MV1184 (obtained from Toyobo). Culture media used were GYP $[2 \%(w / v)$ glucose, $0.5 \%$ yeast extract and $0.5 \%$ peptone] for yeasts and $\mathrm{LB}$ for bacteria. For some experiments, $50 \mu \mathrm{g}$ ampicillin $\mathrm{ml}^{-1}$ was added to the $\mathrm{LB}$ medium. Culture temperatures were $30^{\circ} \mathrm{C}$ for yeasts and $37^{\circ} \mathrm{C}$ for bacteria.

Manipulation of DNA. The plasmid pUC118 (purchased from Takara Shuzo) was used for constructing the gene library and DNA sequencing, and YEp13 (Rose \& Broach, 1991) was used for the transformation of $S$. cerevisiae. All reagents used for DNA manipulations were obtained from Takara Shuzo. Cleavage of DNA with restriction enzymes, ligation of DNA with T4 DNA ligase and exonuclease III treatment of DNA were done as recommended by the suppliers. DNA sequencing was carried out with a $B c a B E S T$ Dideoxy Sequencing kit and an ALF DNA sequencer (Pharmacia Biotech), after nested deletion with exonuclease III. DNA sequences were analysed by GENETYX software (Software Development).

Preparation of DNA. Plasmid DNAs were prepared from E. coli according to the method of Sambrook et al. (1992) Genomic DNA of $T$. penicillatum B2 was prepared by the method of Wach et al. (1994) with minor modifications as follows. T. penicillatum B2 cells cultured until the lateexponential phase in GYP were harvested and used for the preparation of protoplasts. About $10^{8}$ protoplasts prepared by addition of $1000 \mathrm{U}$ Zymolyase 20T (Kirin Brewery) and 1000 U NOVOzyme (NOVO Nordics Japan) in $50 \mathrm{mM}$ EDTA were collected, resuspended in $10 \mathrm{mM}$ Tris $/ \mathrm{HCl}(\mathrm{pH} 8 \cdot 0)$, $10 \mathrm{mM}$ EDTA with $1 \%(\mathrm{w} / \mathrm{v})$ SDS and $1 \mu \mathrm{g}$ proteinase $\mathrm{K} \mathrm{ml}^{-1}$ (Sigma), and lysed by incubation at $60^{\circ} \mathrm{C}$ for $1 \mathrm{~h}$ with occasional shaking. The lysate was mixed with an equal volume of $5 \mathrm{M}$ potassium acetate ( $\mathrm{pH} \mathrm{5.4),} \mathrm{kept} \mathrm{on} \mathrm{ice} \mathrm{for} 1 \mathrm{~h}$ and then centrifuged at $10000 \mathrm{~g}$. Total genomic DNAs were prepared by mixing the supernatant with an equal volume of 2-propanol and by collecting the precipitate with a glass hook. The precipitate was then treated with $10 \mu \mathrm{g}$ RNase A $\mathrm{ml}^{-1}$ (Sigma) and purified by phenol/chloroform $(1: 1, \mathrm{v} / \mathrm{v})$ extraction and precipitation with 2 vols ethanol $(99 \%, \mathrm{v} / \mathrm{v})$.

Transformation. Transformation of E. coli and S. cerevisiae was done by electroporation. Competent E. coli cells were prepared as described by Calvin \& Hanawalt (1988) with minor modifications. E. coli cells cultured until the lateexponential stage for $12 \mathrm{~h}$ at $37^{\circ} \mathrm{C}$ were harvested at $4{ }^{\circ} \mathrm{C}$, washed twice with water at $4{ }^{\circ} \mathrm{C}$, washed twice with $10 \%$ (v/v) glycerol at $4{ }^{\circ} \mathrm{C}$ and resuspended in $10 \%$ glycerol. Recipient $S$. cerevisiae cells were prepared by the method of Becker \& Guarente (1991) with minor modifications as follows. Cells were harvested after culturing in GYP at $30^{\circ} \mathrm{C}$ for $12 \mathrm{~h}$, incubated for $30 \mathrm{~min}$ in TEMEA buffer [ $(10 \mathrm{mM}$ Tris/ $\mathrm{HCl}$ (pH 8.5), $1 \mathrm{mM}$ EDTA, $100 \mathrm{mM} \mathrm{LiCl}$ and $10 \mathrm{mM}$ mercaptoethylamine], washed twice in $1 \mathrm{M}$ sorbitol and then suspended in the same solution.

Electroporation was performed with an Electric Cell Boler 1001 apparatus (Rikokagaku Kenkyusho) as follows. Cell suspensions of E. coli $(40 \mu \mathrm{l})$ and $S$. cerevisiae $(100 \mu \mathrm{l})$ were (a)

Sample $1 \quad \mathrm{~N}-$ E-W-E-G-P-L-I-S-V-S-G-D-S-I-T-V-N-Q-A-S-C

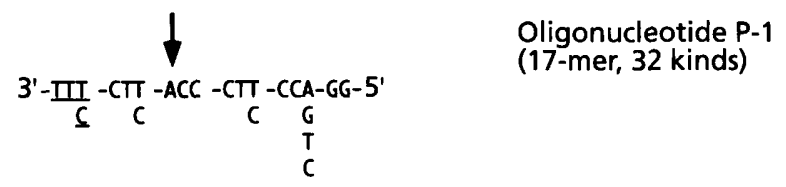

Sample 2 N-G-G-A-C-V-F-K-D-A-Q-S-A-I-A-G-K-A-C

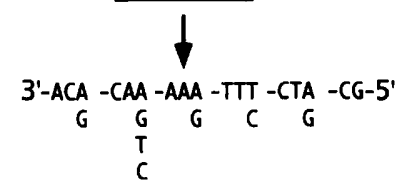

Oligonucleotide P-2

(17-mer, 64 kinds)

(b)

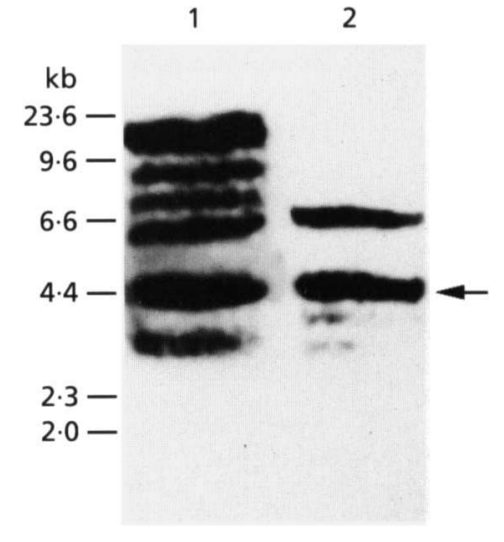

Fig. 1. Southern hybridization. (a) Oligonucleotide sequences used as probes. The sequences were deduced from the boxed amino acid sequences of lysyl endopeptidase digests (a Lys residue was assumed to precede the determined sequence in design of primer $P-1)$. (b) Southern hybridization of $T$. penicillatum B2 genomic DNA digested with HindlII. Probes P-1 (lane 1) and P-2 (lane 2) were hybridized at $35^{\circ} \mathrm{C}$ and washing was done at $43^{\circ} \mathrm{C}$. Molecular size markers (HindIII digests of $\lambda$ DNA) are shown on the left. The arrow indicates the band that is recognized by both probes.

mixed with about $1 \mu \mathrm{g}$ of DNA, transferred to a $0.2 \mathrm{~cm}$ cuvette, and exposed to a single electric pulse $(22 \mathrm{mF}$ capacitance, $4 \mathrm{~ms}$ pulse time, and $25 \mathrm{kV}$ and $15 \mathrm{kV}$ peak voltages, respectively). These voltages generated field strengths in the cuvette up to $12 \mathrm{kV} \mathrm{cm}^{-1}$ and $7 \mathrm{kV} \mathrm{cm}^{-1}$, respectively.

Design of oligonucleotide probes and Southern hybridization. PPase SE1 was digested with Achromobacter lysyl endopeptidase in $50 \mathrm{mM}$ Tris/ $\mathrm{HCl}$ buffer ( $\mathrm{pH} \mathrm{8.0)}$ with $4 \mathrm{M}$ urea. Peptides were prepared by hydrophobic interaction chromatography using an HPLC system with a Capcell C18300 column (Shiseido), and $\mathrm{N}$-terminal amino acid sequences determined using a PSQ1 protein sequencer (Shimadzu). Oligonucleotides corresponding to the predicted DNA sequences from the $\mathrm{N}$-terminal sequences of native PPase SE1 and a fragment from a lysyl endopeptidase digest (Fig. 1a) were labelled with $\left[\gamma^{32} \mathrm{P}\right] \mathrm{ATP}$ (Amersham Japan) with a Megalabel $5^{\prime}$ end-labelling kit. Southern hybridization to gelfractionated total DNA of $T$. penicillatum B2 digested with $H$ indIII and transferred to a cellulose nitrate membrane (Toyo Roshi) was done as described by Sambrook et al. (1992). 
Preparation and screening of gene libraries. The HindIIIdigested genomic DNA was fractionated by electrophoresis in a $0.8 \%$ agarose gel, and fragments of approximately $4.4 \mathrm{~kb}$ which included the probe-hybridizing fragments were purified and inserted into pUC118. Colonies transformed with the gene library were transferred to a cellulose nitrate membrane and hybridized with the oligonucleotide probes according to Sambrook et al. (1992).

Protein analysis. Original PPase SE3 was obtained from our previous study (Iguchi et al., 1996). Partially purified PPase SE3 was prepared from the $S$. cerevisiae transformant as follows. Cells were cultured at $30^{\circ} \mathrm{C}$ for $3 \mathrm{~d}$ with shaking and PGase fractions of the culture filtrate obtained by CMToyopearl 650M (Tosoh) column chromatography were then dialysed in $20 \mathrm{mM}$ acetate buffer (pH 5.0). Approximately $20 \mathrm{mg}$ protein was deglycosylated by digestion with $10 \mathrm{mU}$ endoglycosidase $\mathrm{H}$ (Takara Shuzo) at $37^{\circ} \mathrm{C}$ for $1 \mathrm{~h}$. For Western blotting, about $50 \mu \mathrm{g}$ protein was separated on SDSPAGE gels by the method of Laemmli (1970), transferred to a PVDF membrane (Immobilon, Nihon Millipore) using HolizeBlot (Atto) and analysed by ELISA using an anti-PPase $S$ antibody as a first antibody, peroxidase-labelled protein $A$ (Cosmo Bio) as a second antibody and 3, 3'-diaminobenzidine tetrahydrochloride as a visualizing reagent.

The anti-PPase $S$ antibody, which reacts against PPases SE1, SE2 and SE3, was prepared by the method described by Sakai et al. (1989).

\section{RESULTS AND DISCUSSION}

\section{Cloning of the PPase gene from T. penicillatum}

Two oligonucleotide probes, P-1 and P-2, were synthesized according to the DNA sequences predicted from the $\mathrm{N}$-terminal amino acid sequences of the original PPase SE1 and a fragment of a lysyl endo-

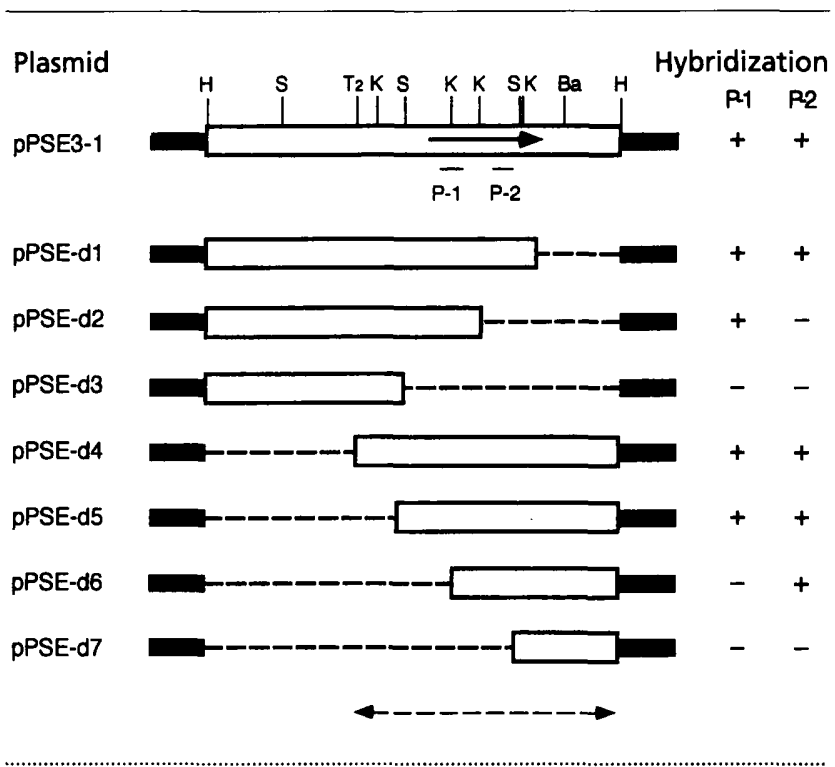

Fig. 2. Restriction map of pPSE3-1 plasmid insert. The single arrow indicates the predicted ORF and the broken double arrow the sequenced region of DNA. The narrow bars show the regions that hybridized with the $\mathrm{P}-1$ and $\mathrm{P}-2$ probes. $\mathrm{H}$, HindIII; K, Kpnl; S, SaCl; T2, EcoT22I; Ba, BamHI.
-142 GATGCTCTGTTAACTATMUTATCTGTGATCGCCTGCAATTATTITITITTTGATAMA -

-82 TCTTCMGCTCMCAACTCTTCTTCTTTGHCTGATMUMGGCCTTATAGACTCTCTTAT

-22 TTGTTCACTCTTACTATMCMTGCTITITTCTMATCTGCTATCTTTGCTATGGCTGC $M$ L F 5 K 5 A I F A M A A P-2

39 TCTTGCAGTTGCTGCTCCTACTGMGGTGACCTTCAGCTCGTGGCAGCGCCIGTGTTT L A V A A T TE GL QARG SA C VF

99 TMGGATGGCMGTCTGCTATTGCTGGCMGUGTCTTTTCTTCTATCACTCTTGGGA K D A K S A I A G K K S S C S S S I T L E N

159 CATTGCTGTCCCGCTGGTCHACTCTIGATCTCACTGGACTTGCCMGGGCACTGTTGT I A $V$ P $P$ A G $G$ Q T $T$ L

219 CACCTITGCTGGTACCACCACTITIGGCTAQMAGGAGGGCTGGTCGTTGATCTCCGT T F A G T T T F G Y K E A G P L I S V

279 TICTGGGATTCTATTACTGTCAGCAGGCCTCCGGCGGMGATTGACTGGGTGGTTC S G $G$ D S S I T T V K K $Q$ Q A

339 TCGTTGGTGGGACGGTMGGGTTCCAACTCTGGTGGTMGCUMAGCCCMGTTCTITIA RW DGK G S N S G G K Q K P K F F Y

399 CGCCCACMGCTCCAGMCTCCAACATTCAGGGACTCCMGTTACHCACCCCTGTCCA

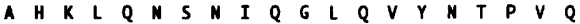

459 GGCTTTCAGCATTTTGTCTGACCATTTGACTTTGTCMACATTCTCGTTGACAACAGAGC A F S I L S D H L T L S N I L V D N R A

519 CGGTGACAGGCTGGTGGTCACACACCGACGCTITTGATTTGGTACCAGTACTTACAT G D K A A G G G H

579 CACTATCGACCATGCTACGGTTACMCCAGGACGACTGTCTTGCTATCMCTCCGGTGA $T$ I D H A T V Y N Q D D C L L A I N S G D

639 CCACATCACTTTCCAGUCGGTTTCTGCTCTGGTGGACATGGTCTTTCTATTGGCTCCGT H I T F Q N G F C S G G H G L S I G S V

699 TGGTGGCCGCTCTCTTMACACTGTITCCMCGTCMTATTCTTMCAGTCAGGTTGTCM G G R S L N T V S N V N I L N S Q V V N

759 CTCTGATMCGGTTCCGTATTMAGACCATTTCTGGTGCTACTGGTTCTGTCAGCGGTGT S D N G V R I K T I S G A T G S V S G V

819 TMGTICCAGGACATTACTCTCTCCACATTGCCMGTACGGTATTGATTTCAGCAGGA K F Q $D$ D I T $T$ L S

879 CTACCGTMCGGGGCCCCACTGGTMCCCCACTMCGGAGTCMGATCACTGGATCGA Y R N G G P T G N P T N G V K I T G I E

939 GTTCATCAССTССGGTAGTGTCMGGGCTCTGGTACCUCGCTTACCTTCTCTGTGG F I N I H G S V K S S G T N A Y L L C G

999 TICCGGCTCTTGCTCCMCTGGACCTGGAGCMGGATCACGTCMGGGTGGCAMGGACAG $S G S C S N W T$ T K I N V K G G K D 5

1659 CGGTGCTTGCMGMCGTCCTTCTGGTGCTACTTGCUACTTTAMTAGCMACTATATA 1118 G A C K N V P S G A T C K L *

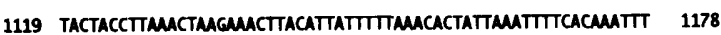
1179 MTACACMUCGTTCMTGMGGGMACCGGGACAGTMGATGAGTGMUCTTGACT 1238 1239 GMTACTTGATTGTATTTGTACTTGTTTAGTMGCCTATMGGATCCATCATTA 1298

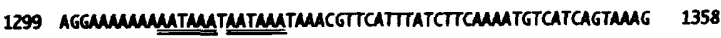

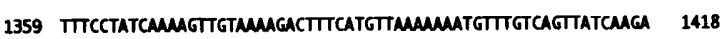
1419 GGTTITCTCTCMTTGTCMGUMATGUACGGACMTTATTCATATTAGMTGTTC 1478

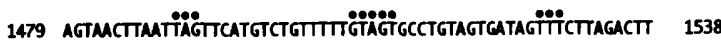
1539 TाTाTCAC

Fig. 3. Nucleotide and predicted amino acid sequences of PSE3. Single-underlined, double-underlined and dotted sequences are a putative TATA-like sequence, polyadenylation signals and termination signals, respectively. Boxed sequences correspond to the complementary sequences of the P-1 and P-2 probes. The amino acid sequence in italics is identical to the determined $\mathrm{N}$ terminal amino acid sequence of mature PPase SE3. The outlined amino acid (Ala87) differs from the corresponding sequence in the $\mathrm{P}-1$ probe. 
(a)

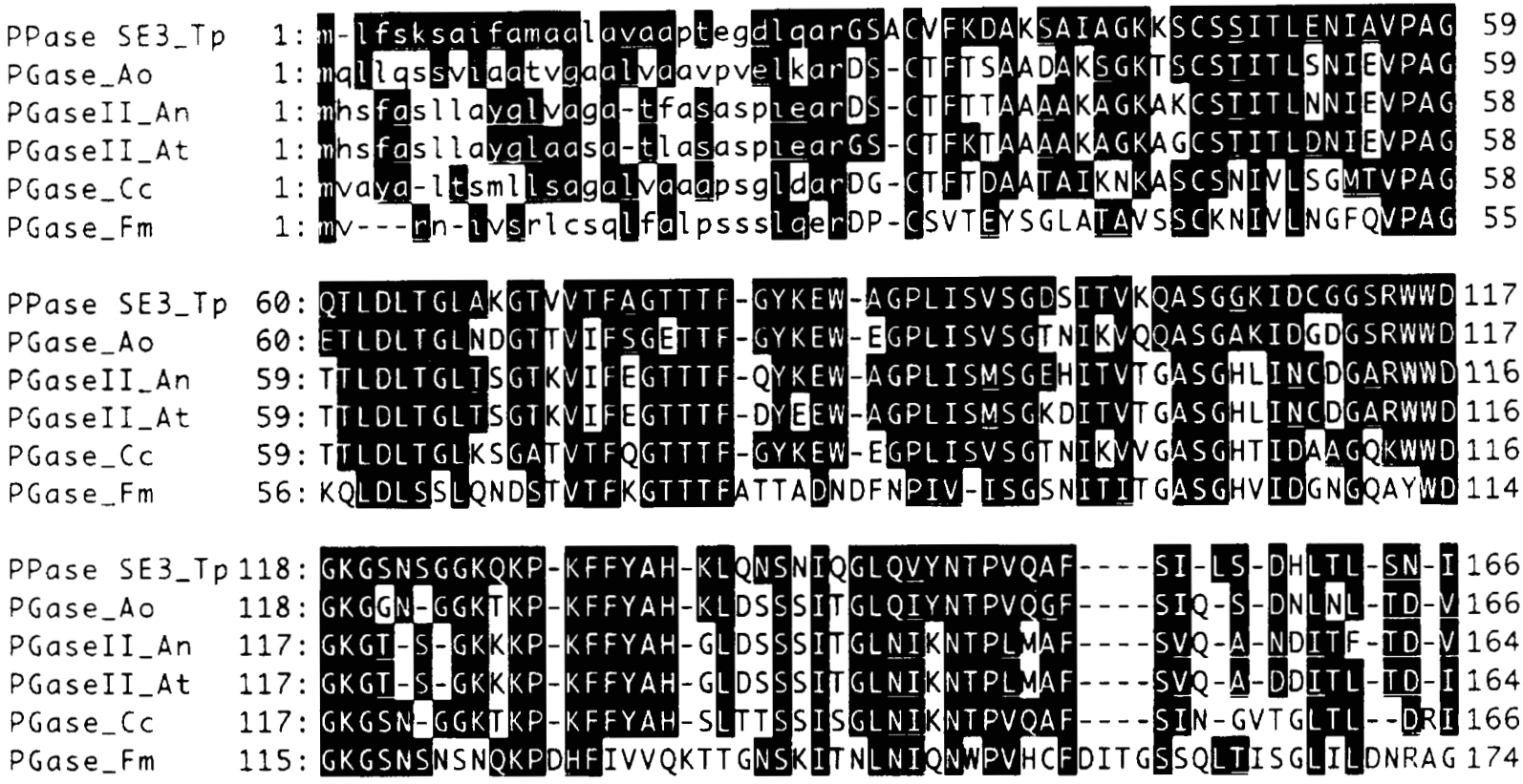

PPase SE3_TP 167: LVDN-RAGDKAGGHNTDAFDVGTSTYITIDHATVYNQDDCLAINSGDHITFQNGFCSGGH 225 PGase_AO 167: TIDN-SAG-TAEGHNTDAFDVGSSTYINIDGATVYNQDOCLAINSGSHITFTNGY CDGGH 224 PGaSeII_An 165: TINN-ADGDTQGGHNTDAFDVGNSVGVNIIKPWNHNQDDCLAVNSGENINFT GGTKIGGH 223 PGaseII_At 165: TINN-ADGDTLGGHNTDAFDVGNSNGVNIIKPWVHNQDDCLA INSGENINFT SGTCIGGH 223 PGase_CC 167: TIDN-SAGDSAGAHNTDAFDIGSSSGITISNANIKNQDDCVAINSGSDIHVTNCQCSGGH 225 PGase_Fm 175: DKPNAKSGSLPAAHNTDGFDISSSDHVTLDNNHVYNQDDCVAVTSGTNINV SNMYCSGGH 234

PPaSe SE3_TP 226: GLSIGSVGGRSLNTVSNVNILNSQVVNSDNGVRIKTVSGATGSVSGVKFQDITLSNIAKY 285 PGaSe_AO 225: GLSIGSVGGRSDNTVEDVTISNSKVVNSQNGVRIKTVYDATGTVSNVKFEDITLSGITKY 284 PGaSEII_An 224: GLSIGSVGDRSNNVVKNVTIEHSTVSNSENAVRIKTISGATGSVSEITYSNIVMSGISDY 283 PGaSEII_AT 224: GLSIGSVGGRSNNVVKNVTIEHSTVSNSENAVRIKTVSGATGSVSEITYSNIVMSGISDY 283 PGase_CC 226: GVSIGSVGGRKDNTVKGVVVSGTTIANSDNGVRIKT ISGATGSVSDITYENITLKNIAKY 285 PGase_Fm 235: GLSIGSVGGKSDNVVDGVQFLSSQVVNSQNGCRIKSNSGATGT INNVTY QN IALTNISTY 294

PPase SE3_TP 286: GIDVQQDYRNGGPTGNPTNGVKITGIEFINIHGSVKSSGTNAYLLCGSGSCSNWTWSKIN 345 PGase_AO 285: GLIVEQDYENGSPTGTPT NGIKVSDITFDKVTGIVESDATDIY ILCGSGSCTGLTWSGVS 344 PGaseII_An 284: GVNIQQDYEDGKPTGKPTNGVTIQDVKLESVTGSVDSGATEIYLLCGSGSCSDWTWDOIK 343 PGaseII_At 284: GVNIQQDYEDGKPT GKPTNGVTITDNKLESNTGTVDSKATDIYLLCGSGSCSDWTWDDVK 343 PGase_CC 286: GIVIEQDYLNGGPTGKPTTGVPITGVTLKNVAGSVTGSGTEIYVLCGKGSC 5 GWNWSGVS 345 PGase_Fm 295: GVDVQQDYLNGGPTGKPTNGVKISNIKEIKVTGTVASSAQDNEILCGDGSCSGFTFSGNA 354

PPase SE3_TP 346: VKGGKDSGACKNVPSGATCKL 366

PGase_AO 345: ITGGKTSSKCENVSTGASC-- 363

PGaseII_An 344: VTGGKKSTACKNFPSNASC-- 362

PGaseII_At 344: VTGGKKSTACKNYPSNASC-- 362

PGase_CC 346: ITGGKKSSSCLNVPSGASC--

PGase_Fm 355: ITGGGKISSC-NYPINT-CPS 373

(b)

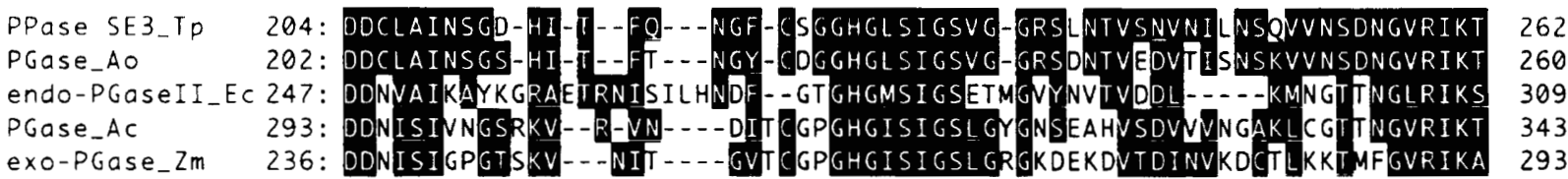

Fig. 4. For legend see facing page. 
peptidase digest (Fig. 1a). Southern hybridization of both sequences to a HindIII digest of the genomic DNA of $T$. penicillatum B2 detected a fragment of about $4.4 \mathrm{~kb}$ (Fig. 1b). This suggested that the gene encoding PPase SE1 might be present on this $4.4 \mathrm{~kb}$ DNA fragment. A gene library was constructed containing HindIII fragments of $4 \cdot 0-4 \cdot 5 \mathrm{~kb}$ in the plasmid pUC118. About $5 \times 10^{3}$ colonies were screened for hybridization to both probes. One such colony was found. A plasmid, pPSE3-1, recovered from this colony hybridized to both the P-1 and P-2 probes. The restriction map of this DNA insert is shown in Fig. 2. The regions that hybridized to the P-1 and P-2 probes were identified using several deletion plasmids (Fig. 2).

\section{Analysis of nucleotide and amino acid sequences of the PPase gene}

About $2 \mathrm{~kb}$ of the cloned DNA sequence (Fig. 2) was determined and is shown in Fig. 3. It contained a predicted ORF of $1101 \mathrm{bp}$ encoding a 367 amino acid protein with a calculated molecular mass of $37967 \mathrm{Da}$. However, the cloned gene did not encode PPase SE1 since the amino acid sequence on which the P-2 probe was based did not completely correspond to that in the predicted ORF. When the N-terminal amino acid sequences of PPases SE1, SE2 and SE3 were compared to the sequenced ORF, amino acids $28-45$ of this ORF were found to completely match the $\mathrm{N}$-terminal sequence of PPase SE3 (Fig. 3). These results indicate that the cloned gene encodes PPase SE3, and this gene was named PSE3.

PSE3 contains no introns, although fungal PGase genes usually contain a few introns. The $\mathrm{G}+\mathrm{C}$ ratio of the PSE3 ORF is $48.9 \mathrm{~mol} \%$. The percentages of $\mathrm{A}, \mathrm{T}, \mathrm{G}$ and $C$ in the third position are 21.6, 29.5, 23.0 and $25.9 \%$, respectively, showing that $\mathrm{T}$ is used in the third position of codons at a relatively high rate. Since the codons in highly expressed genes in fungi show a bias to $C$ in the third position (Gurr et al., 1987), this may indicate that PPase SE3 is produced at a low level by T. penicillatum.

The first 27 amino acid residues of the PSE3 ORF are similar to a processing peptide of the mating pheromones in S. cerevisiae (Julius et al., 1984). This suggests that PPase SE3 is a pre-pro type protein, as are the fungal PGases (Bussink et al., 1991; Kitamoto et al., 1993). Upstream of the mature N-terminal amino acid sequence, the first 17 of the 27 amino acid residues are hydrophobic and are probably a signal peptide, involved in the secretion of PPase SE3. The dipeptide Ala26Arg27 is similar to the processing site of the KEX2 proteinase in $S$. cerevisiae, suggesting that the 10 amino acid residues from Ala18 to Arg27 are processed by a KEX2-like proteinase in T. penicillatum. Mature PPase SE3 is composed of 340 amino acids with a calculated molecular mass of $35204 \mathrm{Da}$. The molecular mass of the original PPase SE3 was estimated to be about $40 \mathrm{kDa}$ by SDS-PAGE (Iguchi et al., 1996). The cause of this size difference is not understood.

\section{Analysis of amino acid sequence of PPase SE3}

The deduced amino acid sequence of PPase SE3 was used to search for homologous sequences in the SWISSPROT database. This sequence showed significant homology to a PGase of Aspergillus oryzae (Kitamoto et al., 1993), PGase II of Aspergillus niger (Bussink et al., 1991), PGase II of Aspergillus tubigensis (Bussink et al., 1991), a PGase of Cochliobolus carbonum (Scott-Craig et al., 1990) and a PGase of Fusarium moniliforme (Caprari et al., 1993). The alignments of these homologous sequences are given in Fig. 4. Sequence similarities were $65.4 \%$ for the PGase of $A$. oryzae, $56.7 \%$ for PGase II of $A$. niger, $58.1 \%$ for PGase II of $A$. tubigensis, $61.8 \%$ for the PGase of C. carbonum and $48.9 \%$ for the PGase of $F$. moniliforme. Except for the PGase of $F$. moniliforme, whole regions of the mature enzymes are conserved (Fig. 4a). In the PGase of $F$. moniliforme, partial regions of the $\mathrm{N}$-terminal sequence, including VTFKGTTTF at positions 69-77, WDGKGSNS at positions 113-120, and the C-terminal region from Ala186 are conserved. The amino acid sequence of PPase SE3 was compared to that of the endo-PGase II of Erwinia carotovora (Saarilahti et al., 1990), the PGase of Actinidia chinensis (kiwifruit) (Atkinson \& Gardner, 1993) and an exo-PGase of Zea mays (Niogret et al., 1991). The similarities with the entire sequences of the bacterial and plant PGases $(24 \cdot 4$, 25.8 and $23.4 \%$, respectively) were lower than with those of the fungi indicating that PPase SE3 is more closely related to the fungal PGases than to the bacterial and the plant PGases. However the sequence from Asp204 to Thr262 in PPase SE3 is highly conserved among these enzymes. Fig. 4(b) shows this sequence in PPase SE3, the PGase of A. oryzae, the endo-PGase II of E. carotovora, the PGase of Act. chinensis and the exoPGase of $Z$. mays. These domains, conserved in fungi, bacteria and higher plants, might correspond to the substrate (i.e. polygalacturonic acid)-binding site and the active centre of the enzyme.

The hydropathy profile of PPase SE3 was compared to those of the five above-mentioned fungal PGases (Fig. 5). The complete profile of PPase SE3 is different from those of the PGases of C. carbonum and F. moniliforme, while the profile of the N-terminal half of PPase SE3 is similar to those of the Aspergillus PGases. The profile of the

Fig. 4. Alignments of $T$. penicillatum PPase SE3 with homologous PGase sequences. (a) Alignment with fungal PGases. PPase SE3_Tp, PPase SE3 of T. penicillatum; PGase_Ao, PGase of A. oryzae, PGasell_An, PGase II of A. niger, PGasell_At, PGase II of A. tubigensis; PGase_CC, PGase of C. carbonum; PGase_Fm, PGase of $F$. moniliforme. (b) Alignments of highly conserved domains with fungal, bacterial and plant PGases. PPase SE3_Tp, PPase SE3 of T. penicillatum; PGase_Ao, PGase of A. oryzae; endo-PGasell_Ec, endo-PGase II of E. carotovora; PGase_Ac, PGase of Act. chinensis; exo-PGase_Zm, exo-PGase of $Z$. mays. Black-boxed letters, with and without underlining, indicate similar and identical amino acids, respectively. Lower case letters indicate the putative signal peptide and propeptide. 
K. IGUCHI and OTHERS
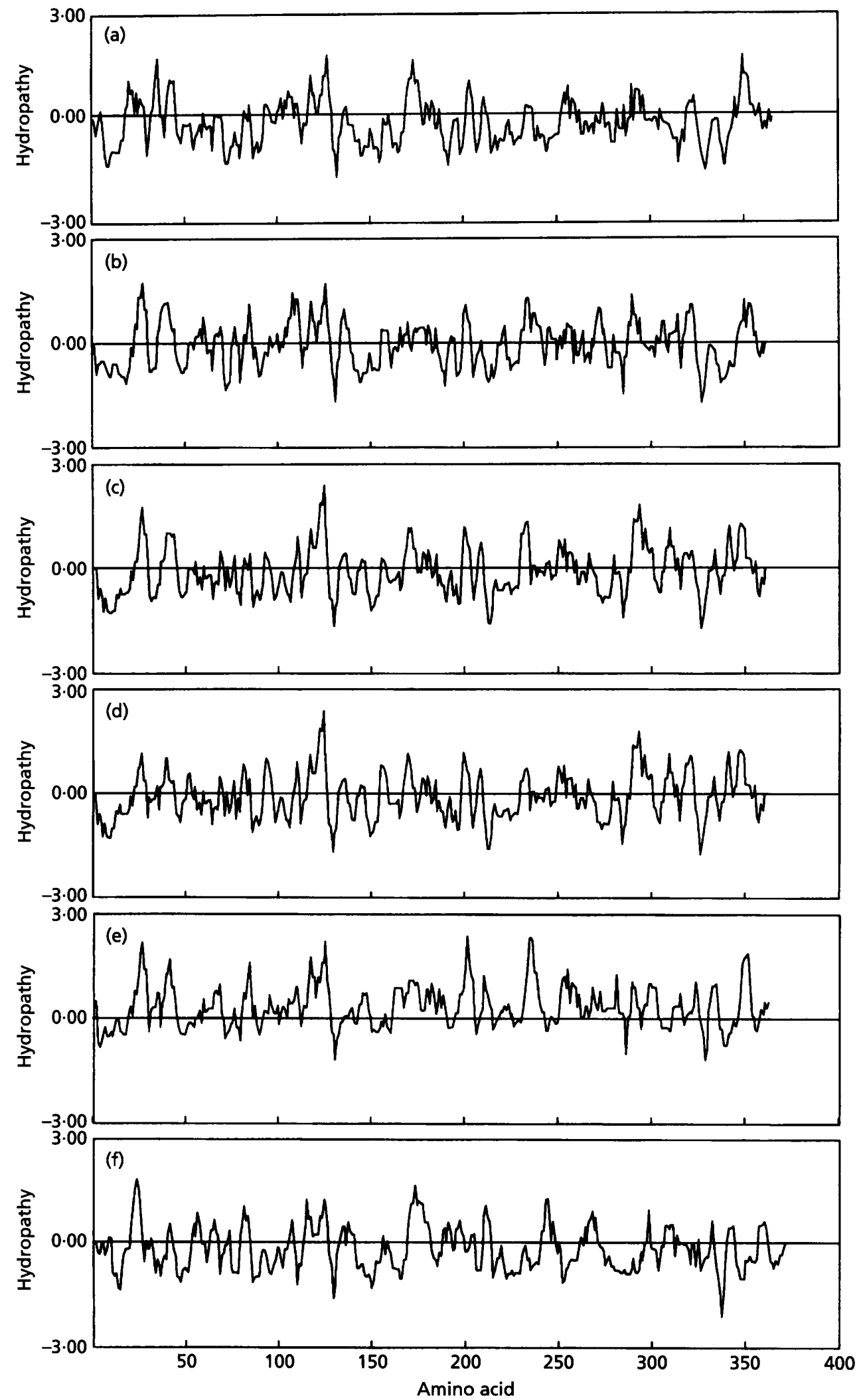

Fig. 5. Hydropathy profiles of PPase SE3 of $T$. penicillatum and fungal PGases. (a) PPase SE3, (b) PGase of A. oryzae, (c) PGase II of $A$. niger, (d) PGase II of A. tubigensis, (e) PGase of C. carbonum, (f) PGase of $F$. moniliforme.

1662 
(a)

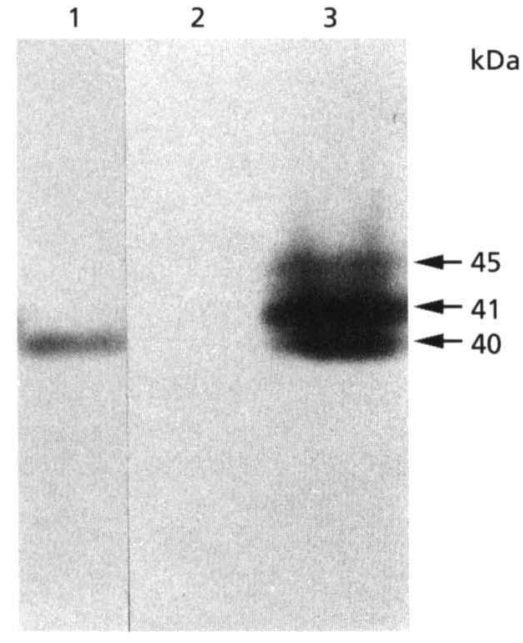

(b)

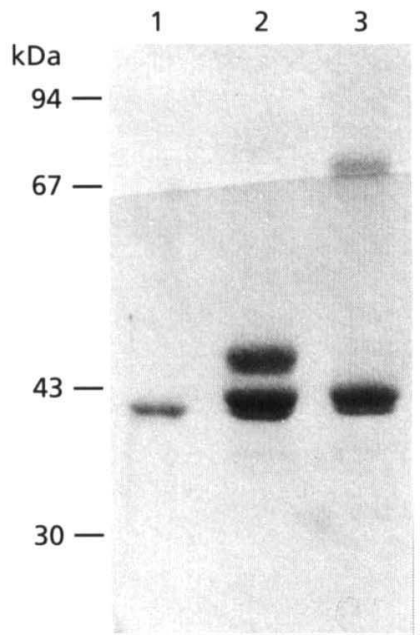

Fig. 6. PPases produced by S. cerevisiae transformants. Protein samples $(50 \mu \mathrm{g})$ were partially purified from culture filtrates by CM-Toyopearl column chromatography. Western analysis was done using anti-PPase S antibody. (a) PPases produced by transformants. Lanes: 1, original PPase SE3; 2, YEp13 transformant; 3, pYEPSE3 transformant. (b) Effect of endoglycosidase $H$ on PPases. Lanes: 1, original PPase SE3; 2 , undigested sample; 3 , sample digested with endoglycosidase $\mathbf{H}$ ( $70 \mathrm{kDa}$ band). Molecular size markers were phosphorylase b (94 kDa), bovine serum albumin (67 kDa), ovalbumin (43 kDa), carbonic anhydrase $(30 \mathrm{kDa})$ and soybean trypsin inhibitor $(20 \mathrm{kDa})$.

region (from Gly158 to Ser266) including the conserved domain of PPase SE3 is similar to the profile of the same region of $A$. oryzae PGase, but slightly different from the profiles of the same regions of the PGase IIs of A. niger and A. tubigensis. These results suggest that the conformation of PPase SE3 is similar to that of the Aspergillus PGases but is slightly different from that of PGase IIs. The $q_{\text {PPase/PGase }}$ ratio of PGase II of A. niger was relatively low $(0.06)$ using lemon peel protopectin as a substrate (unpublished data). PPase SE3 shows relatively high PPase activity ( $\left.q_{\text {PPase/PGase }} 0.93\right)$ using the same substrate (Iguchi et al., 1996). The finding that the PPase activity of PPase SE3 is about 15 -fold greater than that of PGase II of $A$. niger may also indicate that the conserved domain (Asp204-Thr262) of PPase SE3 has a conformation that is different from that of PGase II. These results suggest that this enzyme would be useful for the study of the mechanism of action of PPases.

\section{Characterization of genomic DNA}

When genomic DNA was digested with various restriction enzymes and analysed by Southern hybridization using the PSE3-containing DNA as the probe, three or four bands were obtained from each digest (for example, 4.4, 5.5, 6.5 and 9.0 kb from HindIIIdigested DNA, data not shown). Since one of the bands on all digests is derived from PSE3, the $T$. penicillatum genome possesses two or three copies of the PSE3 homologues. We are trying to isolate these PSE3 homologues, which probably include the genes encoding PPases SE1 and SE2.

\section{Production of PPase SE3 from the PSE3 gene in Saccaromyces cerevisiae}

The cloned DNA fragment containing PSE3 was inserted in the YEp13 vector and the new plasmid, pYEPSE3, was used to transform $S$. cerevisiae DKD-5DH. The transformants were grown in leucine-free medium. PPase SE3 in the culture filtrate of the pYEPSE3 transformant was partially purified and assayed by Western blotting using the anti-PPase $\mathrm{S}$ antibody (Fig. 6a). The pYEPSE 3 transformant produced three proteins that reacted with this antibody. The smallest of these proteins had the same molecular mass (approx. $40 \mathrm{kDa}$ ) as the original PPase SE3 purified from T. penicillatum B2. This result suggests that the promoter of the PSE3 gene was functioning and that PPase SE3 was produced in $S$. cerevisiae. The total PPase production in the culture filtrate of the transformant was about $10^{7}$-fold greater than the PPase SE3 production in the culture filtrate of $T$. penicillatum B2. This may indicate that PSE3 is repressed in B2. The estimated molecular mass of approximately $40 \mathrm{kDa}$ of PPase SE3 produced by the $S$. cerevisiae transformant was also larger than that calculated from the amino acid sequence $(35204 \mathrm{Da})$. The reason for this has not yet been elucidated.

The other two proteins that reacted with the anti-PPase $S$ antibody had larger molecular masses (about 41 and $45 \mathrm{kDa}$ ). When the partially purified enzyme was digested with endoglycosidase $\mathrm{H}$, the largest protein $(45 \mathrm{kDa})$ was not detected (Fig. 6b). This result indicates that the $45 \mathrm{kDa}$ protein is a glycosylated protein derived from PPase SE3 or from the $41 \mathrm{kD}$ a protein. The original PPase SE3 produced by $T$. penicillatum B2 shows a single band on SDS-PAGE gels (Iguchi et al., 1996). This suggests the glycosylation mechanism in the secretion pathway of $S$. cerevisiae is different from that in $T$. penicillatum. Another protein $(41 \mathrm{kDa})$ that was $1 \mathrm{kDa}$ 
larger than PPase SE3 could not be identified. One possibility is that it is a premature enzyme (pro-PPase SE3) that is not processed by the KEX2 proteinase. In $S$. cerevisiae, the KEX2 proteinase recognizes certain dipeptides, such as Arg-Arg, Lys-Arg and Pro-Arg, and cleaves at the C-terminal side of the propeptide (Julius $e t$ al., 1984). The C-terminal dipeptide of the propeptide of pro-PPase SE3 (Ala26-Arg27) differs from that at the cleavage site recognized by the KEX2 proteinase. The cleavage efficiency of the KEX2 proteinase is markedly decreased (by more than $90 \%$ ) when the first amino acid residue of the dipeptide is exchanged for another, such as His (Brennan et al., 1990). We attempted to determine the $\mathrm{N}$-terminal amino acid sequence of the $41 \mathrm{kDa}$ protein, but this band appeared to be contaminated with other proteins (data not shown). If pro-PPase SE3 was incompletely cleaved by the KEX2 proteinase, proPPase SE3, which is probably 10 amino acid residues longer than mature PPase SE3, would be produced by the $S$. cerevisiae transformant. In fact, the transformant produced both PPase SE3 and pro-PPase SE3 (Fig 6b), suggesting that the KEX2 proteinase partially cleaves the Ala-Arg dipeptide residue of pro-PPase SE3.

\section{ACKNOWLEDGEMENTS}

We thank Dr Roque A. Hours (La Plata National University, Argentina) for helpful suggestions and for reading the manuscript.

\section{REFERENCES}

Atkinson, R. G. \& Gardner, R. C. (1993). A polygalacturonase gene from kiwifruit (Actinidia deliciosa). Plant Physiol 103, 669-670.

Becker, D. M. \& Guarente, L. (1991). High-efficiency transformation of yeast by electroporation. Methods Enzymol 194, 182-187.

Brennan, S. O., Peach, R. J. \& Bathurst, I. C. (1990). Specificity of yeast KEX2 protease for variant human proalbumins is identical to the in vivo specificity of the hepatic proalbumin convertase. J Biol Chem 265, 21494-21497.

Bussink, H. J. D., Buxton, F. P. \& Visser., J. (1991). Expression and sequence comparison of the Aspergillus niger and Aspergillus tubigensis genes encoding polygalacturonase II. Curr Genet 19, $467-474$.

Calvin, N. M. \& Hanawalt, P. C. (1988). High-efficiency transformation of bacterial cells by electroporation. J Bacteriol 170, 2797-2801.

Caprari, C., Richter, A., Bergmann, C., Lo Cicero, S., Salvi, G., Cervone, F. \& De Lorenzo, G. (1993). Cloning and characterization of a gene encoding the endopolygalacturonase of Fusarium moniliforme. Mycol Res 97, 497-505.

Gurr, S. J., Unkles, S. E. \& Kinghorn, J. R. (1987). The structure and organization of nuclear genes of filamentous fungi. In Gene
Structure in Eukaryotic Microbes, pp. 93-139. Edited by J. R. Kinghorn. Oxford: IRL Press.

Iguchi, K., Kishida, M. \& Sakai, T. (1996). Purification and characterization of three extracellular protopectinases with polygalacturonase activities from Trichosporon penicillatum. Biosci Biotechnol Biochem 60, 603-607.

Julius, D., Brake, A., Blair, L., Kunisawa, R. \& Thorner, J. (1984). Isolation of the putative structural gene for lysine-argininecleaving endopeptidase required for processing of yeast prepro- $\alpha$ factor. Cell 37, 1075-1089.

Kitamoto, N., Kimura, T., Kito, Y., Ohmiya, K. \& Tsukagoshi, N. (1993). Structural features of a polygalacturonase gene cloned from Aspergillus oryzae KBN616. FEMS Microbiol Lett 111, $37-42$.

Laemmli, U. K. (1970). Cleavage of structural proteins during the assembly of the head of bacteriophage T4. Nature 227, 680-685.

Niogret, M. F., Dubald, M., Mandaron, P. \& Mache, R. (1991). Characterization of pollen polygalacturonase encoded by several cDNA clones in maize. Plant Mol Biol 17, 1155-1164.

Rose, M. D. \& Broach, J. R. (1991). Cloning genes by complementation in yeast. Methods Enzymol 194, 195-230.

Saarilahti, H. I., Heino, P., Pakkanen, R., Kalkkinen, N., Palva, I. \& Palva, E. T. (1990). Structural analysis of the pehA gene and characterization of its protein product, endopolygalacturonase, of Erwinia carotovora subspecies carotovora. Mol Microbiol 4, 1037-1044.

Sakai, T. \& Okushima, M. (1978). Purification and crystallization of a protopectin-solubilizing enzyme from Trichosporon penicillatum. Agric Biol Chem 46, 667-676.

Sakai, T., Okushima, M. \& Yoshitake, S. (1984). Purification, crystallization and some properties of endopolygalacturonase from Kluyveromyces fragilis. Agric Biol Chem 48, 1951-1961.

Sakai, T., Sawada, M., Katsuragi, T. \& Tonomura, K. (1989). Possible role of cell wall mannan in the secretion of the pectinsolubilizing enzyme of Trichosporon penicillatum SNO-3. Agric Biol Chem 53, 9-18.

Sakai, T., Sakamoto, T., Hallaert, J. \& Vandamme, E. J. (1993). Pectin, pectinase, and protopectinase: production, properties, and applications. Adv Appl Microbiol 39, 213-294.

Sambrook, J., Fritsch, E. F. \& Maniatis, T. (1992). Molecular Cloning: a Laboratory Manual, 2nd edn. Cold Spring Harbor, NY: Cold Spring Harbor Laboratory.

Scott-Craig, J. S., Panaccione, D. G., Cervone, F. \& Walton, J. D. (1990). Endopolygalacturonase is not required for pathogenicity of Cochliobolus carbonum on maize. Plant Cell 2, 1191-1200.

Wach, A., Pick, H. \& Philippsen, P. (1994). Procedures for isolating yeast DNA for different purposes. In Molecular Genetics of Yeast: a Practical Approach, pp. 1-16. Edited by J. R. Johnston. Oxford: IRL Press.

Received 1 October 1996; revised 6 January 1997; accepted 13 January 1997. 